\title{
A short-term statin treatment changes the contractile properties of fast-twitch skeletal muscles
}

\author{
Antoine Boulanger Piette ${ }^{1}$, Sébastien S. Dufresne ${ }^{1}$ and Jérôme Frenette ${ }^{1,2^{*}}$
}

\begin{abstract}
Background: Cumulative evidence indicates that statins induce myotoxicity. However, the lack of understanding of how statins affect skeletal muscles at the structural, functional, and physiological levels hampers proper healthcare management. The purpose of the present study was to investigate the early after-effects of lovastatin on the slowtwitch soleus (Sol) and fast-twitch extensor digitorum longus (EDL) muscles.

Methods: Adult C57BL/6 mice were orally administrated with placebo or lovastatin [50 mg/kg/d] for 28 days. At the end of the treatment, the isometric ex vivo contractile properties of the Sol and EDL muscles were measured. Subtetanic and tetanic contractions were assessed and contraction kinetics were recorded. The muscles were then frozen for immunohistochemical analyses. Data were analyzed by two-way ANOVA followed by an a posteriori Tukey's test.

Results: The short-term lovastatin treatment did not induce muscle mass loss, muscle fiber atrophy, or creatine kinase (CK) release. It had no functional impact on slow-twitch Sol muscles. However, subtetanic stimulations at $10 \mathrm{~Hz}$ provoked greater force production in fast-twitch EDL muscles. The treatment also decreased the maximal rate of force development $(\mathrm{dP} / \mathrm{dT})$ of twitch contractions and prolonged the half relaxation time (1/2RT) of tetanic contractions of EDL muscles.

Conclusions: An early short-term statin treatment induced subtle but significant changes in some parameters of the contractile profile of EDL muscles, providing new insights into the selective initiation of statin-induced myopathy in fasttwitch muscles.
\end{abstract}

Keywords: Statin, Myopathy, Muscle, Contractile, Cholesterol

\section{Background}

Statins are a class of drugs used to treat hypercholesterolemia by inhibiting HMG-CoA reductase, which is a ratelimiting step in the biosynthesis of cholesterol. Statins are effective for the primary and secondary prevention of cardiovascular diseases, but their use is frequently associated with statin-induced myopathy (SIM). SIM encompasses myalgia, cramps, weakness, and even rhabdomyolysis [1-3]. While the pathophysiology of SIM is heterogeneous and poorly understood, it appears to be multifactorial and may involve multiple pathophysiological defects, including genetic predisposition [4], early

\footnotetext{
* Correspondence: jerome.frenette@crchul.ulaval.ca

${ }^{1}$ Centre Hospitalier Universitaire de Québec, Centre de Recherche du Centre Hospitalier de l'Université Laval (CHUQ-CHUL), Axe Neurosciences, Université Laval, Quebec City, QC G1V 4G2, Canada

${ }^{2}$ Département de Réadaptation, Faculté de Médecine, Université Laval, Quebec City, QC G1V OA6, Canada
}

(c) The Author(s). 2016 Open Access This article is distributed under the terms of the Creative Commons Attribution 4.0 International License (http://creativecommons.org/licenses/by/4.0/), which permits unrestricted use, distribution, and reproduction in any medium, provided you give appropriate credit to the original author(s) and the source, provide a link to the Creative Commons license, and indicate if changes were made. The Creative Commons Public Domain Dedication waiver (http://creativecommons.org/publicdomain/zero/1.0/) applies to the data made available in this article, unless otherwise stated. [9], the inhibition of protein geranylgeranylation [10], ubiquinone depletion [11, 12], monocarboxylate transporter 4 expression [13, 14], loss of t-tubular region architecture [15, 16], altered membrane fluidity [17], and immune-mediated necrotis [18].

Electrical stimulation causes $\mathrm{Ca}^{2+}$ release from the sarcoplasmic reticulum (SR), triggering actin-myosin crossbridging and muscle contraction. $\mathrm{Ca}^{2+}$ is then rapidly transported back into the SR lumen by SERCA [sarco (endo) plasmic reticulum $\mathrm{Ca}^{2+}$ ATPase], an ATP-dependent $\mathrm{Ca}^{2+}$ pump, inducing muscle relaxation and preparing the muscle for the next contraction. Myoplasmic $\mathrm{Ca}^{2+}$ also regulates protein synthesis, protein degradation, and fiber phenotype by controlling $\mathrm{Ca}^{2+}$-sensitive proteases, transcription factors, and mitochondrial adaptations. Mammalian skeletal muscles contain two SERCA isoforms. 
SERCA-1a is expressed in fast-twitch myofibers while SERCA-2a is usually limited to slow-twitch myofibers [19]. SERCA pumps are defective in several forms of muscle and heart disease, prolonging muscle relaxation and reducing muscle force production $[19,20]$. Impairment of the sarcoplasmic reticulum (SR)/mitochondria $\mathrm{Ca}^{2+}$ release system and the concomitant loss of $\mathrm{Ca}^{2+}$ homeostasis may also be a crucial event leading to SIM [21-23]. A rise in myoplasmic $\mathrm{Ca}^{2+}$ at rest triggers the calmodulin/calcineurin $/ \mathrm{Ca}^{2+/}$ calmodulin-dependent protein kinase II pathway, activating NFATc1 and PGC- $1 \alpha$, two transcription factors and modulators that facilitate the oxidative machinery and slow-twitch phenotype [24, 25]. Interestingly, fasttwitch myofibers, which contain three times more $\mathrm{Ca}^{2+}$ in the SR than slow-twitch myofibers, are the first to disappear in numerous forms of muscle disease and aging [26-28]. These fibers appear to be especially prone to SIM-induced dysfunction and necrosis [29-31]. The failure to preserve physiological resting cytosolic $\mathrm{Ca}^{2+}$ concentrations in SIM may potentially activate the calpain $\mathrm{Ca}^{2+-} \mathrm{de}-$ pendant proteolytic pathway [21], repress protein synthesis $[32,33]$, and stimulate the ubiquitin-proteasome system [34, 35], favoring atrophy [33], myocellular damage [34] and, ultimately, apoptosis [36, 37].

Since statins are widely prescribed and since SIM may lead to the discontinuation of treatment, sometimes after less than 2 weeks, we investigated the functional impact of a short-term lovastatin treatment (28 days) on the ex vivo contractile properties of slow-twitch Sol and fast-twitch EDL muscles We also investigated the impact of a shortterm lovastatin treatment on muscle integrity, serum creatine kinase release, and myosin phenotype in fast-twitch EDL muscles. We showed that lovastatin caused subtle early-stage functional changes in EDL muscles but not in Sol muscles. The functional changes were not accompanied by morphological or phenotypic changes.

\section{Methods}

Animals and experimental design

Male C57BL/6 mice (30-35 g) obtained from Charles River Laboratories International (St-Constant, QC, Canada) were housed one per cage, maintained in a $12 \mathrm{~h}$ light/dark cycle, and given food and water ad libitum. The mice were orally administered with placebo gelatin gel or lovastatin [50 mg/kg/day; J\&K scientific, Shanghai, China] for 28 days $(n=8)$. Lovastatin was chosen for its lipophilic nature, mid-range potency and clinical relevance. The dosage is commonly used and was selected because the HMG-CoA reductase activity and pharmacokinetics of lovastatin are different in rodents and humans [38-40]. The Animal Care and Use Committee of the CHUQ Research Centre approved all the experiments, which complied with Canadian Council on Animal Care guidelines.

\section{Isometric contractile properties}

After a 28-day lovasatin treatment and $24 \mathrm{~h}$ after the last dose of lovastatin, the mice were injected with buprenorphine $[0.1 \mathrm{mg} / \mathrm{kg}]$ for analgesia and pentobarbital sodium [50 $\mathrm{mg} / \mathrm{kg}$ ] for anesthesia. The depth of analgesia/ anesthesia was monitored by pinching the Achilles tendon. The Sol and EDL muscles were completely resected from the hindlimb, attached to a lever arm system (305BLR dual-mode; Aurora Scientific, Canada) controlled by dynamic muscle control and data acquisition software (Aurora Scientific Inc., Aurora, ON, Canada), and incubated at $25{ }^{\circ} \mathrm{C}$ in an oxygenated Krebs-Ringer solution supplemented with $2 \mathrm{mg} / \mathrm{mL}$ of glucose [41, 42]. During the ex-vivo equilibrium period, contralateral muscles were collected and the mice were euthanized by cervical dislocation under anesthesia. Once the optimal length (Lo) and twitch contractions had been determined, the muscles were stimulated for $500 \mathrm{~ms}$ at $10,20,50,80,100$, or $120 \mathrm{~Hz}$ to induce subtetanic and tetanic contractions. Time-to-peak twitch tension (TPT, ms), half relaxation time (1/2 RT), (ms), twitch tension (Pt, g), maximum tetanic tension $\left(\mathrm{P}_{0}, \mathrm{~g}\right)$, and peak rate of tension development $(\mathrm{dP} / \mathrm{dT})$ values were also recorded. At the end of the contractile property measurements, the lengths of the muscles were measured. The tendons were removed, and the muscles were weighed, embedded and frozen in isopentane cooled in liquid nitrogen, and stored at $-80{ }^{\circ} \mathrm{C}$ until used for the immunohistochemical assays. The mice were then euthanized by cervical dislocation under anesthesia.

Enzymatic assays and immunohistochemical experiments Serum creatine kinase activity was determined using a colorimetric assay kit (BioVision, USA). To assess muscle atrophy, the Sol and EDL muscles were perpendicularly sectioned $(10 \mu \mathrm{m})$, stained with hemotoxylin and eosin (H\&E; Sigma-Aldrich, USA), and observed using an inverted light microscope, (Nikon, Canada). Crosssectional areas (CSA) were analyzed using ImageJ software 1.46r (NIH, USA). Myosin heavy chain (MyHC) I and MyHC II antibodies (Leica Biosystems, Canada) were used to determine changes in fast and slow phenotypes in EDL muscles. Approximately 100 myofibers per muscle were quantified. All values are expressed as means \pm standard errors of the mean. Data were analyzed by two-way ANOVA (InStat software, v.3). When a significant F ratio was obtained, an a posteriori Tukey's test was performed. The level of significance was set at $p<0.05$.

\section{Results}

To investigate the effect of lovastatin on muscle atrophy, the masses and CSA of Sol and EDL muscles from placebo and statin-treated mice were determined. The 28-day statin treatment had no significant effect on muscle mass or CSA values (Tables 1 and 2). Serum creatine kinase levels, 
Table 1 Morphology and contractile properties of Sol muscles

\begin{tabular}{lll}
\hline Measure & Placebo & Lovastatin \\
\hline Muscle mass; $(\mathrm{mg})$ & $10,79 \pm 0,10$ & $10,92 \pm 0,76$ \\
Cross-sectional area; $\left(\mu \mathrm{m}^{2}\right)$ & $1101,98 \pm 78,55$ & $1146,79 \pm 88,46$ \\
Twitch tension Pt; $(\mathrm{g})$ & $3,25 \pm 0,28$ & $3,81 \pm 0,51$ \\
Maximal tetanic force $\mathrm{P}_{0} ;(\mathrm{g})$ & $22,72 \pm 1,11$ & $25,72 \pm 0,45^{p=0.053}$ \\
Specific force $\mathrm{SP}_{0}$; $(\mathrm{g} / \mathrm{mg})$ & $2,18 \pm 0,09$ & $2,38 \pm 0,09$ \\
Pt/Po & $0,14 \pm 0,01$ & $0,14 \pm 0,02$ \\
Time to peak tension TPT; (ms) & $52,14 \pm 2,15$ & $47,83 \pm 3,28$ \\
1/2 RT at Pt; (ms) & $47,14 \pm 2,59$ & $47,01 \pm 2,30$ \\
\hline
\end{tabular}

The treatment with lovastatin [50 $\mathrm{mg} / \mathrm{kg} /$ day] for 28 days had the tendency $(0,05<p<0,06)$ to increase the maximum tetanic force $\left(P_{0}\right)$ of Sol muscles. Data are expressed as means $\pm \mathrm{SE}, n=8$ mice for each experimental group. The level of significance was set at ${ }^{*} p<0.05$

which are a biomarker of muscle damage, were below the limit of detection. Hematoxylin and eosin (H\&E) staining revealed no significant muscle damage in the control and statin-treated mice (Fig. 1).

To characterize the impact of lovastatin on muscle function, we measured the ex vivo contractile properties of the Sol and EDL muscles. The control and statintreated slow-twitch Sol muscles had similar contraction magnitude and kinetics values (Table 1, Fig. 2a, c, d). The absolute force production of the Sol muscles from the statin-treated mice tended to increase $(p<0.06)$ when stimulated at 50, 80, 100 and $120 \mathrm{~Hz}$ (Fig. 2a). However, when the force production was normalized with mass, the Sol muscles from the control and statintreated mice displayed similar levels of specific tetanic force production (Table 1). The lovastatin treatment did not affect the TPT, Pt $/ \mathrm{P}_{0}$, or Pt $1 / 2 \mathrm{RT}$ values (Table 2 ) of fast-twitch EDL muscles. However, the treatment significantly decreased the maximal rate of tension generation (dP/dT) for twitch contractions (Pt) by $22.4 \%$ (Fig. 2c) and significantly prolonged the $1 / 2$ RT for tetanic

Table 2 Morphology and contractile properties of extensor digitorum longus muscles

\begin{tabular}{lll}
\hline Measure & Placebo & Lovastatin \\
\hline Muscle mass; $(\mathrm{mg})$ & $11,89 \pm 0,76$ & $12,71 \pm 0,10$ \\
Cross-sectional area; $\left(\mathrm{\mu m}^{2}\right)$ & $1154,36 \pm 115,02$ & $1285,96 \pm 64,05$ \\
Twitch tension Pt; $(\mathrm{g})$ & $4,82 \pm 0,37$ & $6,25 \pm 0,633^{p=0.088}$ \\
Maximal tetanic force $\mathrm{P}_{0} ;(\mathrm{g})$ & $28,83 \pm 2,23$ & $30,37 \pm 2,67$ \\
Specific force $\mathrm{SP}_{0}$; $(\mathrm{g} / \mathrm{mg})$ & $2,45 \pm 0,16$ & $2,39 \pm 0,20$ \\
Pt/Po & $0,17 \pm 0,01$ & $0,20 \pm 0,01$ \\
Time to peak tension TPT; (ms) & $27,71 \pm 1,54$ & $29,83 \pm 2,62$ \\
1/2 RT at Pt; (ms) & $14,43 \pm 1,14$ & $17,00 \pm 1,00$
\end{tabular}

The treatment with lovastatin [50 mg/kg/day] for 28 days had the tendency $(0,05<p<0,09)$ to increase the twitch tension (Pt) of EDL muscles. Data are expressed as means $\pm S E, n=8$ mice for each experimental group. The level of significance was set at ${ }^{*} p<0.05$ contractions $\left(\mathrm{P}_{0}\right)$ by $48.7 \%$ in fast-twitch EDL muscles from statin-treated mice compared to EDL muscles from the control mice (Fig. 2d). In addition, the force production at $10 \mathrm{~Hz}$ of EDL muscles from the statin-treated mice was significantly higher $(36.7 \%$ gain) than EDL muscles from the control mice (Fig. 2b). Despite the tendency for force to increase at 1 and $20 \mathrm{~Hz}(p<0.06$ statistical trend), there were no significant differences at higher stimulation frequencies (50-120 Hz) (Fig. 2b).

Since these changes in the contractile profiles were suggestive of changes in muscle phenotype, we quantified the percentage of fast $\mathrm{MyHC}$ isoform. The changes in the contractile profile of EDL muscles were not associated with significant changes in the proportion of fibers expressing fast $\mathrm{MyHC}$ isoform (98 \% fast $\mathrm{MyHC}$ in EDL muscles) following the lovastatin treatment (data not shown).

\section{Discussion}

SIM has major social and economic consequences. The lack of understanding of how statins impair muscle function at the molecular, cellular, and physiological levels creates numerous barriers to effective treatment [2]. SIM can result in the discontinuation of treatment, leaving specific patients at risk of potential adverse cardiovascular events [43]. The onset of SIM is most likely multifactorial, resulting in multiple physiological impairments in patients with ill-defined musculoskeletal conditions. We showed that a short-term lovastatin treatment induces subtle but significant changes in the contractile profile of fast-twitch EDL muscles.

We also showed that a short-term 28-day lovastatin treatment did not affect the morphology, integrity, or maximal force output of slow-twitch Sol and fast-twitch EDL muscles. However, the force production of subtetanic contractions at $10 \mathrm{~Hz}$ was significantly higher while the $1 / 2 \mathrm{RT}$ at $\mathrm{P}_{0}$ of EDL muscles was prolonged in statin-treated mice compared to control mice. From a physiological standpoint, a prolonged $1 / 2 \mathrm{RT}$ at $\mathrm{P}_{0}$ should favor a longer lasting $\mathrm{Ca}^{2+}$ transient, leading to a gain of force production at a low frequency stimulation $(10 \mathrm{~Hz})$. Furthermore, the prolonged $1 / 2$ RT in fast-twitch EDL muscles also suggested that $\mathrm{Ca}^{2+}$ reuptake by the SR is impaired. $\mathrm{Ca}^{2+}$ reuptake is almost exclusively mediated by SERCA-1a in fast-twitch fibers. SERCA is critical for $\mathrm{Ca}^{2+}$ homeostasis and reuptake by the SR following contractions, allowing cytosolic $\mathrm{Ca}^{2+}$ concentrations to return to baseline levels and enabling muscle relaxation $[19,44]$. Consistent with our results and a role for statins in the regulation of $\mathrm{Ca}^{2+}$ handling, chronic 2month-long treatments of rats with fluvastatin $[20 \mathrm{mg} / \mathrm{kg}]$ increase the resting cytosolic $\mathrm{Ca}^{2+}$ concentration of EDL muscle fibers by $60 \%$ but have no impact on muscle integrity and grip strength [21]. Pierno et al. (1999) also reported that EDL muscles from simvastatin-treated rats require less 


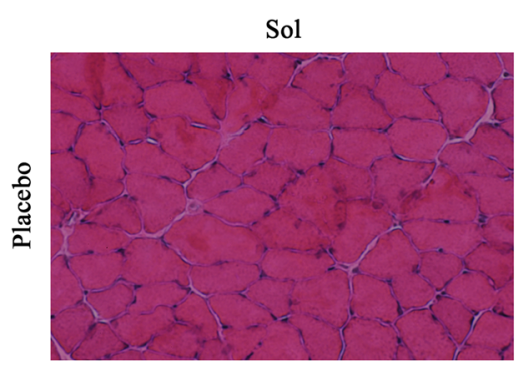

EDL
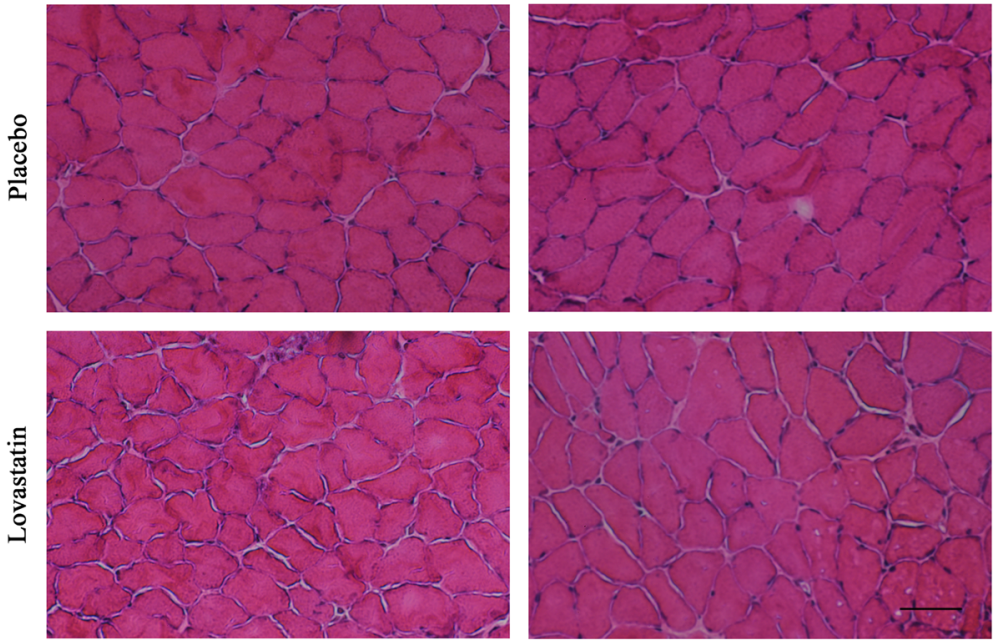

Fig. 1 Cross-sections of soleus and extensor digitorum longus muscles stained with hematoxylin and eosin. There were no significant differences in the structure and histologic features of Sol and EDL muscles following placebo or lovastatin [50 mg/kg/day] treatments. Scale bar $=100 \mu \mathrm{m}$
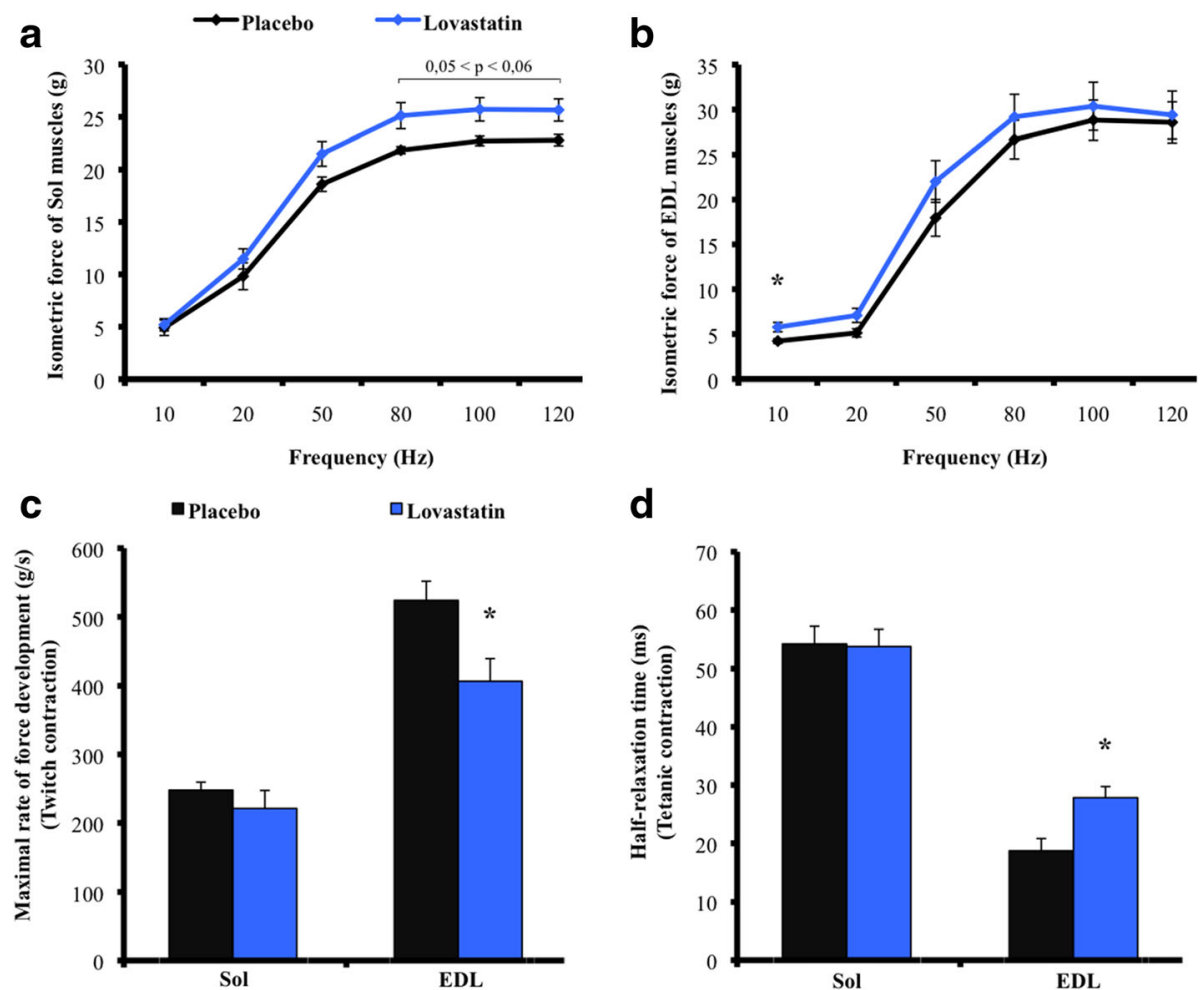

d

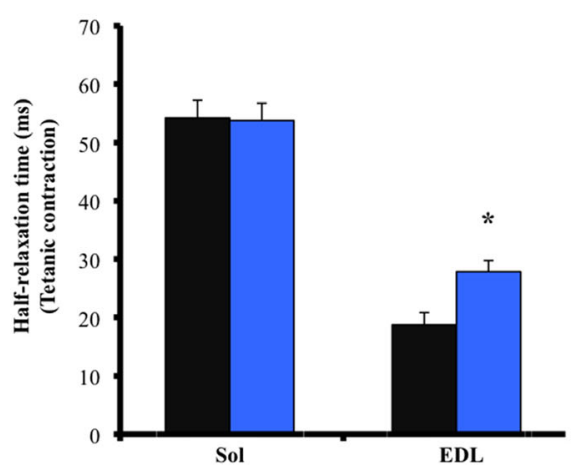

Fig. 2 Contractile properties of soleus and extensor digitorum longus muscles in placebo and lovastatin-treated mice. Frequency-force relationships for Sol (a) and EDL muscles (b). Maximal rate of force development of twitch contractions (c) and half-relaxation time of tetanic contractions (d) in Sol or EDL muscles following placebo or lovastatin [50 mg/kg/day] treatments for 28 days. The absolute force production of the Sol muscles from the statin-treated mice tended to increase $(p<0.06)$ when stimulated at $50,80,100$ and $120 \mathrm{~Hz}$. The treatment significantly decreased the maximal rate of tension generation ( $\mathrm{dP} / \mathrm{dT}$ ) for twitch contractions (Pt) by $22.4 \%$ and significantly prolonged the $1 / 2$ RT for tetanic contractions $\left(P_{0}\right)$ by $48.7 \%$ in fast-twitch EDL muscles from statin-treated mice compared to EDL muscles from the control mice. Data are expressed as means $\pm \mathrm{SE}, n=8$ for each experimental group. The level of significance was set at ${ }^{*} p<0.05$ 
depolarization to contract, suggesting that they contain higher levels of cytosolic $\mathrm{Ca}^{2+}$ [45]. Liantonio et al. (2007) proposed that mitochondria are responsible for the earlier event, with a subsequent and larger $\mathrm{Ca}^{2+}$ leakage from SR stores, and that extracellular $\mathrm{Ca}^{2+}$ channels play a negligible role in the increase in cytosolic $\mathrm{Ca}^{2+}$. Applying simvastatin to human skeletal muscle fibers triggers a wave of cytosolic $\mathrm{Ca}^{2+}$ originating from the SR $\mathrm{Ca}^{2+}$ store, while ryanodine and SERCA inhibitors almost completely abolish the increase in cytosolic $\mathrm{Ca}^{2+}$ [46]. These findings indicated that the loss of $\mathrm{Ca}^{2+}$ homeostasis associated with SIM may be caused by the release of $\mathrm{Ca}^{2+}$ from mitochondria and/or the SR store $[21,22,46]$. The prolonged $1 / 2 \mathrm{RT}$ and gain of force at a low stimulation frequency provide additional support for the notion that $\mathrm{Ca}^{2+}$ handling is impaired, especially in fast-twitch muscles, following statin treatments.

We also showed that the maximum $\mathrm{dP} / \mathrm{dT}$, i.e. the peak rate of force development, is $22.4 \%$ lower in EDL muscles from statin-treated mice. A decrease in $\mathrm{dP} / \mathrm{dT}$ should be associated with a change in muscle phenotype from fastto slow-twitch. In rats, a simvastatin-treatment induces a $15 \%$ shift from the fast $\mathrm{MyHC} \mathrm{IIb/x}$ to the slower MyHC IIa phenotype, which is associated with a loss of power output $(-41 \%)$ and a reduced shortening velocity $(-23 \%)$, with no change in isometric force or CK levels [47]. However, we did not detect any phenotypic changes in EDL muscles after the 28-day lovastatin treatment. Since cholesterol plays a pivotal role in the composition, fluidity, and integrity of the cell membrane, it is possible that statin treatments alter the compliance/rigidity of the muscle membrane, thus decreasing $\mathrm{dP} / \mathrm{dT}$. In other words, the contractile component shortens and stretches the elastic component (membrane, extracellular matrix, tendon) by the same amount during contractions. A more compliant membrane/extracellular matrix in statin-treated mice would lower $\mathrm{dP} / \mathrm{dT}$. Accordingly, statins cause a deterioration of the biomechanical properties of the Achilles tendon [48] and may be a risk factor for muscle and tendon ruptures and tendinopathies $[49,50]$. Statins have thus pleiotropic properties, but the exact mechanism by which they decrease $\mathrm{dP} / \mathrm{dT}$ requires further investigation.

\section{Conclusions}

Our results provide additional support for the observation that statin treatments have an impact on fast-twitch muscles but have no effect on the function of slow-twitch muscles. Fast-twitch myofibers are also more vulnerable to dysfunction in several forms of muscle disease [51-53]. The changes in the contractile profiles of EDL muscles have also been observed in young and healthy mice treated with a physiological dose of statin. Statins are often prescribed to elderly patients, who are often sarcopenic and undergo a gradual change toward a slow-myofiber phenotype [54,55]. Would these changes in contractile properties be greater in patients with chronic conditions? Would this shift toward slow phenotype increase the risk of falls given that explosive bursts of strength and power are needed to prevent falls? In this context, it would be relevant to determine whether statin treatments exacerbate aging-induced muscle dysfunction and whether the prevalence of SIM is higher in patients with chronic physical conditions. Further animal and human investigations are warranted to determine how statins induce SIM and muscle dysfunction.

\section{Abbreviations \\ 1/2 RT: Half relaxation time; CK: Creatine kinase; CSA: Cross-sectional aera; dP/ dT: Maximal rate of force development; EDL: Extensor digitorum longus; H\&E: Hematoxylin \& eosin; Lo: Optimal lenght; MyHC: Myosin heavy chain; $P_{0}$ : Maximum tetanic tension; Pt: Twitch tension; SERCA: Sarco-endoplasmic reticulum calcium ATPase; SIM: Statin-induced myopathy; Sol: soleus; \\ SR: Sarcoplasmic reticulum; TPT: Time to peak tension}

\section{Acknowledgements}

The authors wish to thank the Natural Sciences and Engineering Research Council of Canada (NSERC) and the Canadian Institutes of Health Research (CIHR) for funding this research.

\section{Funding}

This work was supported by grants to J. Frenette from the Natural Sciences and Engineering Research Council of Canada (NSERC) and the Canadian Institutes of Health Research (CIHR).

Availability of data and materials

Datasets will be available from the authors upon request.

Authors' contributions

A.B.P. and J.F. designed the research protocol; A.B.P. performed the experiments; A.B.P. and S.S.D. analyzed the data; A.B.P. and J.F. interpreted the results; A.B.P. prepared the figures; A.B.P., S.S.D. and J.F. drafted, edited, revised, and approved the final version of the manuscript.

Competing interests

The authors declare that they have no competing interests.

Consent for publication

Not applicable.

Ethics approval and consent to participate

The Animal Care and Use Committee of the CHUQ Research Centre approved all the experiments based on Canadian Council on Animal Care guidelines (\# 2011-169-1).

Received: 22 May 2016 Accepted: 21 October 2016

Published online: 28 October 2016

\section{References}

1. Boulanger-Piette A, Bergeron J, Desgreniers J, Côté-Levesque M, Brassard D, Joanisse DR, et al. Statin intolerance and associated muscular dysfunctions. Médecine Sci MS. 2015;31:1109-14.

2. Taha DA, De Moor CH, Barrett DA, Gershkovich P. Translational insight into statin-induced muscle toxicity: from cell culture to clinical studies. Transl Res J Lab Clin Med. 2014;164:85-109.

3. Egan A, Colman E. Weighing the benefits of high-dose simvastatin against the risk of myopathy. N Engl J Med. 2011;365:285-7.

4. SEARCH Collaborative Group, Link E, Parish S, Armitage J, Bowman L, Heath $\mathrm{S}$, et al. SLCO1B1 variants and statin-induced myopathy-a genomewide study. N Engl J Med. 2008;359:789-99.

5. Kwak H-B, Thalacker-Mercer A, Anderson EJ, Lin C-T, Kane DA, Lee N-S, et al Simvastatin impairs ADP-stimulated respiration and increases mitochondrial oxidative stress in primary human skeletal myotubes. Free Radic Biol Med. 2012:52:198-207. 
6. Sirvent P, Fabre O, Bordenave S, Hillaire-Buys D, Raynaud De Mauverger E, Lacampagne A, et al. Muscle mitochondrial metabolism and calcium signaling impairment in patients treated with statins. Toxicol Appl Pharmacol. 2012:259:263-8.

7. Stringer HAJ, Sohi GK, Maguire JA, Côté HCF. Decreased skeletal muscle mitochondrial DNA in patients with statin-induced myopathy. J Neurol Sci. 2013;325:142-7

8. Muraki A, Miyashita K, Mitsuishi M, Tamaki M, Tanaka K, Itoh H. Coenzyme Q10 reverses mitochondrial dysfunction in atorvastatin-treated mice and increases exercise endurance. J Appl Physiol Bethesda Md. 2012;113:479-86.

9. Siddals KW, Marshman E, Westwood M, Gibson JM. Abrogation of insulinlike growth factor-I (IGF-I) and insulin action by mevalonic acid depletion: synergy between protein prenylation and receptor glycosylation pathways. J Biol Chem. 2004;279:38353-9.

10. Yu J-G, Sewright K, Hubal MJ, Liu J-X, Schwartz LM, Hoffman EP, et al. Investigation of gene expression in $\mathrm{C}(2) \mathrm{C}(12)$ myotubes following simvastatin application and mechanical strain. J Atheroscler Thromb. 2009;16:21-9.

11. Folkers $K$, Langsjoen $P$, Willis $R$, Richardson $P$, Xia $L$, Ye CQ, et al. Lovastatin decreases coenzyme Q levels in humans. Proc Natl Acad Sci U S A. 1990;87: $8931-4$

12. Willis RA, Folkers $K$, Tucker $J$, Ye $C Q$, Xia LJ, Tamagawa H. Lovastatin decreases coenzyme Q levels in rats. Proc Natl Acad Sci U S A. 1990;87:8928-30.

13. Kikutani Y, Kobayashi M, Konishi T, Sasaki S, Narumi K, Furugen A, et al. Involvement of Monocarboxylate Transporter 4 Expression in Statin-Induced Cytotoxicity. J Pharm Sci. 2016;105:1544-9.

14. Sirvent $P$, Bordenave $S$, Vermaelen $M$, Roels B, Vassort G, Mercier J, et al. Simvastatin induces impairment in skeletal muscle while heart is protected. Biochem Biophys Res Commun. 2005;338:1426-34.

15. Mohaupt MG, Karas RH, Babiychuk EB, Sanchez-Freire V, Monastyrskaya K, lyer $L$, et al. Association between statin-associated myopathy and skeletal muscle damage. CMAJ Can Med Assoc J J Assoc Medicale Can. 2009;181:E11-8.

16. Draeger A, Monastyrskaya K, Mohaupt M, Hoppeler H, Savolainen H, Allemann C, et al. Statin therapy induces ultrastructural damage in skeletal muscle in patients without myalgia. J Pathol. 2006;210:94-102.

17. Evans M, Rees A. The myotoxicity of statins. Curr Opin Lipidol. 2002;13:415-20.

18. Lahaye $C$, Beaufrére AM, Boyer $O$, Drouot L, Soubrier M, Tournadre A. Immune-mediated myopathy related to anti 3-hydroxy-3-methylglutarylcoenzyme A reductase antibodies as an emerging cause of necrotizing myopathy induced by statins. Jt Bone Spine Rev Rhum. 2014;81:79-82.

19. Periasamy M, Kalyanasundaram A. SERCA pump isoforms: their role in calcium transport and disease. Muscle Nerve. 2007;35:430-42.

20. Pan X, Liu J, Nguyen T, Liu C, Sun J, Teng Y, et al. The physiological role of mitochondrial calcium revealed by mice lacking the mitochondrial calcium uniporter. Nat Cell Biol. 2013;15:1464-72.

21. Liantonio A, Giannuzzi V, Cippone V, Camerino GM, Pierno S, Camerino DC. Fluvastatin and atorvastatin affect calcium homeostasis of rat skeletal muscle fibers in vivo and in vitro by impairing the sarcoplasmic reticulum/ mitochondria Ca2 +-release system. J Pharmacol Exp Ther. 2007;321:626-34.

22. Inoue R, Tanabe M, Kono K, Maruyama K, Ikemoto T, Endo M. Ca2 + -releasing effect of cerivastatin on the sarcoplasmic reticulum of mouse and rat skeletal muscle fibers. J Pharmacol Sci. 2003;93:279-88.

23. Tanaka S, Sakamoto K, Yamamoto M, Mizuno A, Ono T, Waguri S, et al. Mechanism of statin-induced contractile dysfunction in rat cultured skeletal myofibers. J Pharmacol Sci. 2010;114:454-63.

24. Norrbom J, Sundberg CJ, Ameln H, Kraus WE, Jansson E, Gustafsson T. PGC1alpha mRNA expression is influenced by metabolic perturbation in exercising human skeletal muscle. J Appl Physiol Bethesda Md. 2004;96:189-94.

25. Eilers W, Jaspers RT, de Haan A, Ferrié C, Valdivieso P, Flück M. CaMKII content affects contractile, but not mitochondrial, characteristics in regenerating skeletal muscle. BMC Physiol. 2014;14:7.

26. Sugiura T, Miyata $H$, Kawai $Y$, Matoba H, Murakami N. Changes in myosin heavy chain isoform expression of overloaded rat skeletal muscles. Int J Biochem. 1993;25:1609-13.

27. Webster C, Silberstein L, Hays AP, Blau HM. Fast muscle fibers are preferentially affected in Duchenne muscular dystrophy. Cell. 1988;52:503-13.

28. Lexell J, Taylor CC, Sjöström M. What is the cause of the ageing atrophy? Total number, size and proportion of different fiber types studied in whole vastus lateralis muscle from 15-to 83-year-old men. J Neurol Sci. 1988;84:275-94.

29. Simsek Ozek N, Bal IB, Sara Y, Onur R, Severcan F. Structural and functional characterization of simvastatin-induced myotoxicity in different skeletal muscles. Biochim Biophys Acta. 1840;2014:406-15.
30. Westwood FR, Bigley A, Randall K, Marsden AM, Scott RC. Statin-induced muscle necrosis in the rat: distribution, development, and fibre selectivity. Toxicol Pathol. 2005;33:246-57.

31. Seachrist JL, Loi C-M, Evans MG, Criswell KA, Rothwell CE. Roles of exercise and pharmacokinetics in cerivastatin-induced skeletal muscle toxicity. Toxicol Sci Off J Soc Toxicol. 2005:88:551-61.

32. Tuckow AP, Jefferson SJ, Kimball SR, Jefferson LS. Simvastatin represses protein synthesis in the muscle-derived $\mathrm{C}_{2} \mathrm{C}_{12}$ cell line with a concomitant reduction in eukaryotic initiation factor 2B expression. Am J Physiol Endocrinol Metab. 2011; 300:E564-70.

33. Mallinson JE, Constantin-Teodosiu D, Sidaway J, Westwood FR, Greenhaff PL Blunted Akt/FOXO signalling and activation of genes controlling atrophy and fuel use in statin myopathy. J Physiol. 2009:587:219-30.

34. Hanai J, Cao P, Tanksale P, Imamura S, Koshimizu E, Zhao J, et al. The musclespecific ubiquitin ligase atrogin-1/MAFbx mediates statin-induced muscle toxicity. J Clin Invest. 2007;117:3940-51

35. Urso ML, Clarkson PM, Hittel D, Hoffman EP, Thompson PD. Changes in ubiquitin proteasome pathway gene expression in skeletal muscle with exercise and statins. Arterioscler Thromb Vasc Biol. 2005:25:2560-6.

36. Sacher J, Weigl L, Werner M, Szegedi C, Hohenegger M. Delineation of myotoxicity induced by 3-hydroxy-3-methylglutaryl CoA reductase inhibitors in human skeletal muscle cells. J Pharmacol Exp Ther. 2005;314:1032-41.

37. Johnson TE, Zhang X, Bleicher KB, Dysart G, Loughlin AF, Schaefer WH, et al. Statins induce apoptosis in rat and human myotube cultures by inhibiting protein geranylgeranylation but not ubiquinone. Toxicol Appl Pharmacol. 2004:200:237-50.

38. Kita T, Brown MS, Goldstein JL. Feedback regulation of 3-hydroxy-3methylglutaryl coenzyme A reductase in livers of mice treated with mevinolin, a competitive inhibitor of the reductase. J Clin Invest. 1980;66:1094-100.

39. Dostal LA, Whitfield LR, Anderson JA. Fertility and general reproduction studies in rats with the HMG-CoA reductase inhibitor, atorvastatin. Fundam Appl Toxicol Off J Soc Toxicol. 1996;32:285-92.

40. Cilla DD, Whitfield LR, Gibson DM, Sedman AJ, Posvar EL. Multiple-dose pharmacokinetics, pharmacodynamics, and safety of atorvastatin, an inhibitor of HMG-CoA reductase, in healthy subjects. Clin Pharmacol Ther. 1996:60:687-95.

41. Dufresne SS, Dumont NA, Bouchard P, Lavergne É, Penninger JM, Frenette J. Osteoprotegerin protects against muscular dystrophy. Am J Pathol. 2015; 185:920-6.

42. Dumont NA, Frenette J. Macrophage colony-stimulating factor-induced macrophage differentiation promotes regrowth in atrophied skeletal muscles and C2C12 myotubes. Am J Pathol. 2013;182:505-15.

43. Turin A, Pandit J, Stone NJ. Statins and Nonadherence: Should We RELATE Better? J Cardiovasc Pharmacol Ther. 2015;20:447-56.

44. Tupling AR. The sarcoplasmic reticulum in muscle fatigue and disease: role of the sarco(endo)plasmic reticulum Ca2 +-ATPase. Can J Appl Physiol Rev Can Physiol Appliquée. 2004:29:308-29.

45. Pierno S, De Luca A, Liantonio A, Camerino C, Conte CD. Effects of HMGCoA reductase inhibitors on excitation-contraction coupling of rat skeletal muscle. Eur J Pharmacol. 1999;364:43-8.

46. Sirvent $P$, Mercier J, Vassort $G$, Lacampagne A. Simvastatin triggers mitochondriainduced $\mathrm{Ca} 2+$ signaling alteration in skeletal muscle. Biochem Biophys Res Commun. 2005:329:1067-75.

47. Trapani L, Melli L, Segatto M, Trezza V, Campolongo P, Jozwiak A, et al. Effects of myosin heavy chain (MHC) plasticity induced by HMGCoAreductase inhibition on skeletal muscle functions. FASEB J Off Publ Fed Am Soc Exp Biol. 2011;25:4037-47.

48. Kaleağasıoğlu F, Olcay E, Olgaç V. Statin-induced calcific Achilles tendinopathy in rats: comparison of biomechanical and histopathological effects of simvastatin, atorvastatin and rosuvastatin. Knee Surg Sports Traumatol Arthrosc Off J ESSKA. 2015;77:50-7.

49. Thomsen LL, Laursen JO. Spontaneous bilateral quadriceps tendon rupture in obese patient medicated with statin. Ugeskr Laeger. 2014; 176:V09140471.

50. Ekhart C, De Jong La W, Gross-Martirosyan LD, Van Hunsel FP M. Muscle rupture associated with statin use. Br J Clin Pharmacol. 2016;82:473-7.

51. Arnardottir S, Borg K, Ansved T. Sporadic inclusion body myositis: morphology, regeneration, and cytoskeletal structure of muscle fibres. Neurol Neurosurg Psychiatry. 2004;75:917-20.

52. Lexell J. Human aging, muscle mass, and fiber type composition. J Gerontol A Biol Sci Med Sci. 1995;50:11-6. 
53. Kelly FJ, Goldspink DF. The differing responses of four muscle types to dexamethasone treatment in the rat. Biochem J. 1982;208:147-51.

54. Brown M, Hasser EM. Complexity of age-related change in skeletal muscle. J Gerontol A Biol Sci Med Sci. 1996;51:B117-23.

55. Chan S, Head SI. Age-and gender-related changes in contractile properties of non-atrophied EDL muscle. PLoS ONE. 2010;5, e12345.

Submit your next manuscript to BioMed Central and we will help you at every step:

- We accept pre-submission inquiries

- Our selector tool helps you to find the most relevant journal

- We provide round the clock customer support

- Convenient online submission

- Thorough peer review

- Inclusion in PubMed and all major indexing services

- Maximum visibility for your research

Submit your manuscript at www.biomedcentral.com/submit 